Article

\title{
Study on Climate and Grassland Fire in HulunBuir, Inner Mongolia Autonomous Region, China
}

\author{
Meifang Liu ${ }^{1}$, Jianjun Zhao ${ }^{1}$, Xiaoyi Guo ${ }^{1}$, Zhengxiang Zhang ${ }^{1, *}$, Gang Tan ${ }^{2}$ and Jihong Yang ${ }^{2}$ \\ 1 Provincial Laboratory of Resources and Environmental Research for Northeast China, \\ Northeast Normal University, Changchun 130024, China; liumf985@nenu.edu.cn (M.L.); \\ zhaojj662@nenu.edu.cn (J.Z.); guoxy914@nenu.edu.cn (X.G.) \\ 2 Jilin Surveying and Planning Institute of Land Resources, Changchun 130061, China; \\ tangang156@163.com (G.T.); yangjh123@hotmail.com (J.Y.) \\ * Correspondence: zhangzx040@nenu.edu.cn; Tel.: +86-186-0445-1898
}

Academic Editors: Jason Levy and George Petropoulos

Received: 15 January 2017; Accepted: 13 March 2017; Published: 17 March 2017

\begin{abstract}
Grassland fire is one of the most important disturbance factors of the natural ecosystem. Climate factors influence the occurrence and development of grassland fire. An analysis of the climate conditions of fire occurrence can form the basis for a study of the temporal and spatial variability of grassland fire. The purpose of this paper is to study the effects of monthly time scale climate factors on the occurrence of grassland fire in HulunBuir, located in the northeast of the Inner Mongolia Autonomous Region in China. Based on the logistic regression method, we used the moderate-resolution imaging spectroradiometer (MODIS) active fire data products named thermal anomalies / fire daily L3 Global 1km (MOD14A1 (Terra) and MYD14A1 (Aqua)) and associated climate data for HulunBuir from 2000 to 2010, and established the model of grassland fire climate index. The results showed that monthly maximum temperature, monthly sunshine hours and monthly average wind speed were all positively correlated with the fire climate index; monthly precipitation, monthly average temperature, monthly average relative humidity, monthly minimum relative humidity and the number of days with monthly precipitation greater than or equal to $5 \mathrm{~mm}$ were all negatively correlated with the fire climate index. We used the active fire data from 2011 to 2014 to validate the fire climate index during this time period, and the validation result was good (Pearson's correlation coefficient was 0.578), which showed that the fire climate index model was suitable for analyzing the occurrence of grassland fire in HulunBuir. Analyses were conducted on the temporal and spatial distribution of the fire climate index from January to December in the years 2011-2014; it could be seen that from March to May and from September to October, the fire climate index was higher, and that the fire climate index of the other months is relatively low. The zones with higher fire climate index are mainly distributed in Xin Barag Youqi, Xin Barag Zuoqi, Zalantun Shi, Oroqen Zizhiqi, and Molidawa Zizhiqi; the zones with medium fire climate index are mainly distributed in Chen Barag Qi, Ewenkizu Zizhiqi, Manzhouli Shi, and Arun Qi; and the zones with lower fire climate index are mainly distributed in Genhe Shi, Ergun city, Yakeshi Shi, and Hailar Shi. The results of this study will contribute to the quantitative assessment and management of early warning and forecasting for mid-to long-term grassland fire risk in HulunBuir.
\end{abstract}

Keywords: HulunBuir; grassland fire; logistic regression; fire climate

\section{Introduction}

Grassland fire is one of the most important disturbance factors of natural disturbance to the ecosystem, and poses a very critical problem [1-3]. Natural and human factors have a great impact on the occurrence and spread of grassland fires [4], and grassland fire is a major disaster in the world 
today. It has a great impact and a strong destructive influence on the ecological balance. The area of global grassland affected by fire is $73,619.16 \mathrm{~km}^{2}$ [5]. Statistics show that China's grassland area is approximately $4 \times 10^{6} \mathrm{~km}^{2}$, accounting for $41.7 \%$ of China's land area, with fire-prone areas accounting for one third and frequent fire area accounting for one sixth [6]. Grassland fire disasters bring huge losses to livestock development and endanger human lives and grassland ecosystems [7].

Grassland fire occurrence is susceptible to weather and climate [8-10]. Weather and climate factors exert a great impact on determining the fire regime of a region [11-13], affecting the combustibility of fuel through sunshine hours, temperature, precipitation, atmospheric humidity and wind speed directly. Therefore, it could be argued that climate conditions determine the monthly changes in grassland fires. On a long-term scale, the time, intensity and frequency of grassland fire occurrence vary greatly in time and space, and have significant seasonality [14]. The "fire season" refers to the time or season in a region where fire occurred and whose temperature is relatively high, precipitation is relatively low, and combustibles are dry. Local-scale controls on fire regimes are always dominated by regional climate influences [15-17].

In the savannah grassland of Africa, most of the fire appears in the dry season (June-August) [18,19]. The occurrence of grassland fire in the north of China mainly appears in the spring (March to June) and autumn (September to November) and the grassland fire season lasts for 7 months of the year $[20,21]$. The temporal distribution of grassland fires in HulunBuir is closely related to the climate characteristics of this region [22].

Forest fire has been better studied than grassland fire, and research on grassland fire generally has been concentrated on grassland fire hazards [23,24]. Grassland fire potential can be assessed at any scale based on long-term and short-term indices, or with integrated rating systems that include both long-term and short-term variables to produce the potential fire environment [25]. The study on short-term fire weather is more extensive, as is that on climate and fire occurrence, which has examined the spatial and temporal relationships between fire occurrence and climate conditions [26-28]. At present, related domestic and foreign research has mostly focused on the fire weather index, which aims to capture the driving effect of climate factors on grassland fire occurrence [29-31]. Studies of a fire weather index are usually divided into two parts. Firstly, they integrate the meteorological factors with grassland fire events to establish the fire weather index, which is classified into rating classes in order to interpret the severity of fire events. Researchers around the world have used meteorological indicators to build a large number of fire weather classification models and fire risk indices $[13,32,33]$, though most are focused on forest fire and relatively few pertain to grassland fire. Internationally, the United States and Canada were the first countries to conduct studies on forest fire risk and thus have obtained the most research [34]. The United States developed a national fire risk forecasting system in 1972 and improved it in 1978; it has been widely used throughout the world [35]. Canada began to conduct forest fire studies in the 1920s. The Canadian fire weather indicator system, issued in 1974, is based on a plethora of ignition test and meteorological data, from the theory of moisture balance of combustible materials, through a series of derivations and calculations, and, finally, to fire weather indicators (FWI) [36]. Since the 1950s, forest fire research has been carried out in China, and in the 1970-1980s, more than 10 kinds of fire weather forecasting methods were developed. With the development of GIS technology, remote sensing technology and mathematical modelling techniques, forest fire forecasting has been vastly improved [37]. However, the grassland fire weather index model only reflects the short-term meteorological factors in grassland fire events. Short-term meteorological factors cannot fully explain their effect on grassland fire occurrence, so there should also be medium and long-term scale driving effects of climate factors on grassland fire occurrence. Secondly, researchers employ a larger spatiotemporal scale to study the risk of fire occurrence, fire season, fire intensity and fire behavioral changes caused by climate change [38-40]. Climate change plays an important role in temporal and spatial variations in fire seasonality in some regions [2], also affecting the fire frequency, fire season length and fire area [41]. On a large spatial scale, climate exerts a synchronizing and regional control on fire occurrence [42]. 
In summary, the statistical methods of meteorological factors and fire occurrence events are established by principal component analysis and cluster analysis, and focus on the application of the existing fire weather indexes in grassland fires.

Fire ignition datasets can be obtained from satellite observations [43]. Using the moderateresolution imaging spectroradiometer (MODIS) active fire products MOD14A1 (Terra) and MYD14A1 (Aqua) and related climate data, the model of fire climate index is established based on the logistic regression method for HulunBuir. On the monthly time scale, the spatial and temporal distribution pattern of fire climate is analyzed in terms of the climate conditions that can affect grassland fire occurrence, which is the basis for the research and analysis of the temporal and spatial variability of grassland fire. This study of the grassland fire climate lays the foundation for the study of the medium and long-term climate with respect to fire and provides a theoretical basis for a medium and long-term early warning and forecasting systems for disaster prevention and reduction of grassland fire occurrence.

\section{Material and Methods}

\subsection{Study Area}

The study area is administered by HulunBuir of the Inner Mongolia Autonomous Region in China, which is within $115.22-126.06^{\circ} \mathrm{E}$ and $47.08-53.23^{\circ} \mathrm{N}$. The study area covers an area of $252,948 \mathrm{~km}^{2}$, and comprises 13 counties (Figure 1). The topography becomes gradually flatter with a decrease in elevation from the center to the east and to the west. The area of the Grassland in HulunBuir is approximately $83,000 \mathrm{~km}^{2}$. The study area has a typical temperate continental monsoon climate; the annual precipitation is approximately $250 \mathrm{~mm}$ to $400 \mathrm{~mm}$ with a decrease from southeast to northwest, while the average annual temperature is approximately $-3{ }^{\circ} \mathrm{C}$ to $0{ }^{\circ} \mathrm{C}$ with a general decrease in temperature from southeast to northwest. The study area is dry and windy in spring and warm briefly in summer. Temperatures drop quickly and frost begins early in autumn, and winter is long and cold. The aridity indices of April and September are higher than other months. The vegetation in the region is diverse, including meadow steppe, typical steppe and desert steppe from east to west.

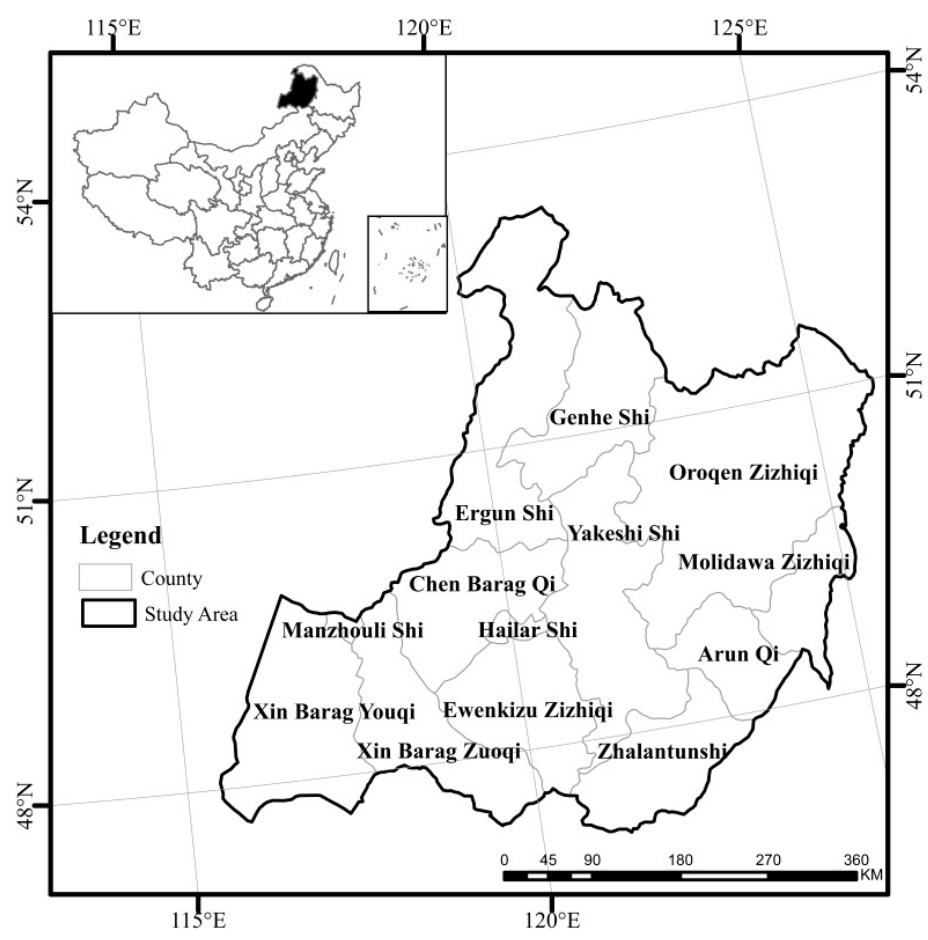

Figure 1. The location of the study area. 


\subsection{Data}

\subsubsection{Grassland Active Fire Data}

The active fire data of MOD14A1 (Terra) and MYD14A1 (Aqua) from 2000 to 2014 are both downloaded from the level-1 and atmosphere archive \& distribution system, distributed active archive center and both data products are 8-day composite level 3 fire products [44]. The region included four images, h25v03, h25v04, h26v03 and h26v04, all of which used the MODIS standard sub-frame. The product has a spatial resolution of $1 \mathrm{~km}$ and a temporal resolution of 1 day. Each grid cell was capable of daily detection of fire occurrence, and eight-day data were packed into a single folder.

\subsubsection{Climate Data}

Climate data from nine meteorological stations in HulunBuir for the period from January 2000 to December 2014 were compiled, including the following parameters: monthly average temperature, monthly maximum temperature, monthly average relative humidity, monthly average wind speed, monthly minimum relative humidity, monthly precipitation, monthly sunshine hours, monthly number of days with precipitation greater than or equal to $1 \mathrm{~mm}$, monthly number of days with precipitation greater than or equal to $2.5 \mathrm{~mm}$, monthly number of days with precipitation greater than or equal to $5 \mathrm{~mm}$, monthly maximum wind speed, and monthly maximum daily precipitation.

\subsubsection{Land Use Data}

To extract the distribution of grassland fire points more accurately, land use data were used to determine the distribution of grassland resources and to remove the non-grassland fire points. Landsat7 TM satellite imagery of August in 2010 was used, with a spatial resolution of $30 \mathrm{~m}$ and a time resolution of 16 days. Data were obtained from the Institute of Remote Sensing and Digital Earth, Chinese Academy of Earth Observation Data Sharing Service Web site [45]. Radiation correction, atmospheric correction, projection transformation, mosaic, and cutting were used to process the image data. In the ENVI software, the land use data of the study area were obtained by using the supervised classification method.

\subsection{Methods}

\subsubsection{Extraction of Grassland Active Fire Data}

The MODIS Reprojection Tool (MRT) is a tool for mosaic, resampling and re-projection of multiple images processed by the NASA website, which can run MODIS data in the JAVA environment. The MRT can be used to select arbitrary bands of MODIS data and to read and process MODIS data in HDF format. By using MRT, the data to be processed can be converted into the projection required by the user, as well as converted to the GeoTIFF or HDF format supported by most software. In this paper, the MRT has been used to mosaic four images every 8 days, and the nearest neighbor method was selected for re-projection.

The MODIS original sinusoidal projection is converted to the Albers area projection, and the original MODIS data in HDF format are converted to the GeoTIFF format. The original data of MOD14A1/MYD14A1 consist of four kinds of fire information: Fire Mask, Quality Assurance (QA), Maximum Fire Radiative Power (FRP), and Scan Sample. The Fire Mask section is used here. The data of MOD14A1 and MYD14A1 with MRT resampling and re-projection are mainly used in the Fire Mask, where each 8-bit unsigned dataset is stored for each daily fire occurrence, and each pixel is assigned a value from 0 to 9 (Table 1 ). 
Table 1. MOD14A1/MYD14A1 fire mask pixel classes.

\begin{tabular}{cc}
\hline Class & Meaning \\
\hline 0 & Not processed (missing input data) \\
2 & Not processed (other reason) \\
3 & Water \\
4 & Cloud \\
5 & Non-fire clear land \\
6 & Unknown \\
7 & Low-confidence fire \\
8 & Nominal-confidence fire \\
9 & High-confidence fire \\
\hline
\end{tabular}

By using the mask extraction tool in ArcGIS software, the MRT-processed image data are extracted. To produce the image of the study area, HulunBuir's administrative boundary is used to cut the extracted image.

We extract the data of three levels, 7 (Low Confidence), 8 (Medium Confidence), and 9 (High Confidence), to obtain all the fire points of the 2000-2014 study area.

Thirty-meter grassland land use data from 2010 are used to screen the data to obtain the annual grassland fire points.

\subsubsection{Establishment of Fire Climate Model}

The grassland fire climate index is used to express the probability of grassland fire occurrence on any day of the month. Therefore, logistic regression was used to establish the fire climate index model. The number and spatial distribution of non-fire points are critical to the assessment of the fire climate index model. In this paper, the spatial distribution of non-fire points is randomly generated in ArcGIS. The number of grassland fire points from January 2000 to December 2010 was collected and counted. There were 132 months from 2000 to 2010, of which 101 months had grassland fire points and 31 months had no grassland fire points. For a month with grassland fire points, an equal number of non-fire points are randomly generated; for a month without grassland fire points, the number of non-fire points is equal to the average number of grassland fire points of 101 months. The probability of the grassland fire points was recorded as 1 and that of the non-fire points as 0 .

Spatial distributions of the climate parameters, including monthly average temperature, monthly maximum temperature, monthly average relative humidity, monthly average wind speed, monthly minimum relative humidity, monthly precipitation, monthly sunshine hours, monthly number of days with precipitation greater than or equal to $1 \mathrm{~mm}$, monthly number of days with precipitation greater than or equal to $2.5 \mathrm{~mm}$, monthly number of days with precipitation greater than or equal to $5 \mathrm{~mm}$, monthly maximum wind speed, and monthly maximum daily precipitation from January 2000 to December 2010, were obtained in ArcGIS by using Kriging interpolation. Based on the logistic regression model in SPSS, the stepwise variable approach was adopted to establish the relationship between the random occurrence probability of grassland fire and the climate parameters; the grassland fire climate index model is therefore given as below:

$$
\begin{gathered}
P=\frac{1}{1+\exp ^{-z}} \\
Z=b_{0}+b_{1} x_{1}+b_{2} x_{2}+\ldots+b_{i} x_{i}
\end{gathered}
$$

In this model, $P$ is the grassland fire climate index, which represents the probability of the random occurrence of grassland fire in a month; $Z$ is a linear combination of independent variables, $x_{i}$ is the value of the $i_{t h}$ climate factor; $b_{0}$ is the constant of the model; and $b_{i}$ is the regression coefficient of climate factor $x_{i}$. 


\subsubsection{Accuracy Assessment of the Model}

The receiver operator characteristic (ROC) curve is a statistical method widely used to comprehensively assess the performance of classifiers [46,47]. The area under ROC curve (AUC) for the fire climate index model indicated the model prediction accuracy.

The climate data from January to December of 2011-2014 were interpolated by Kriging to obtain monthly spatial distribution data for each climate parameter, which were then substituted into the fire climate index model, and the spatial distribution of fire climate index in the study area was calculated monthly. The monthly mean value of the fire climate index in 13 counties from January to December of the years 2011-2014 was obtained using statistical tools. We calculated the monthly mean of the fire points in 13 counties from January to December of 2011-2014 and performed a Pearson correlation analysis between the calculated result and the monthly mean of the fire climate index of the corresponding month. The Pearson correlation coefficient can be used to verify the model.

\subsubsection{Classification of Fire Climate Zones}

Utilizing the ArcGIS software, this paper classified the fire climate index from January to December of 2011-2014 with the equal interval classification method. The fire climate index was divided into five classes, including an extremely low fire climate index zone $(P<0.2)$, a low fire climate index zone $(0.2<P<0.4)$, a medium fire climate index zone $(0.4<P<0.6)$, a high fire climate index zone $(0.6<P<0.8)$ and an extremely high fire climate index zone $(0.8<P<1)$.

\section{Results}

\subsection{Distribution of Active Fires}

After extracting of grassland active fire data, the distribution map of grassland active fire data of HulunBuir from 2000 to 2014 was obtained (Figure 2 and Table 2). For the period from 2000 to 2014, the total number of grassland active fire points was 5565 in the study area. On the inter-annual scale, the number of grassland active fire points in 2000 was the highest, with 913. In 2004, the number of grassland active fire points was the lowest, with 138. On the inter-monthly scale, grassland fires occurred mainly in April, May, September and October; in January and December, the occurrences of grassland fires were the lowest. In the spatial distribution, the occurrence of grassland fires appeared mainly in Oroqen Zizhiqi, Molidawa Zizhiqi, Arun Qi, Zalantun Shi, Chen Barag Qi and Manzhouli $\mathrm{Shi}$; the number of grassland fire occurrences in other counties was relatively low. 


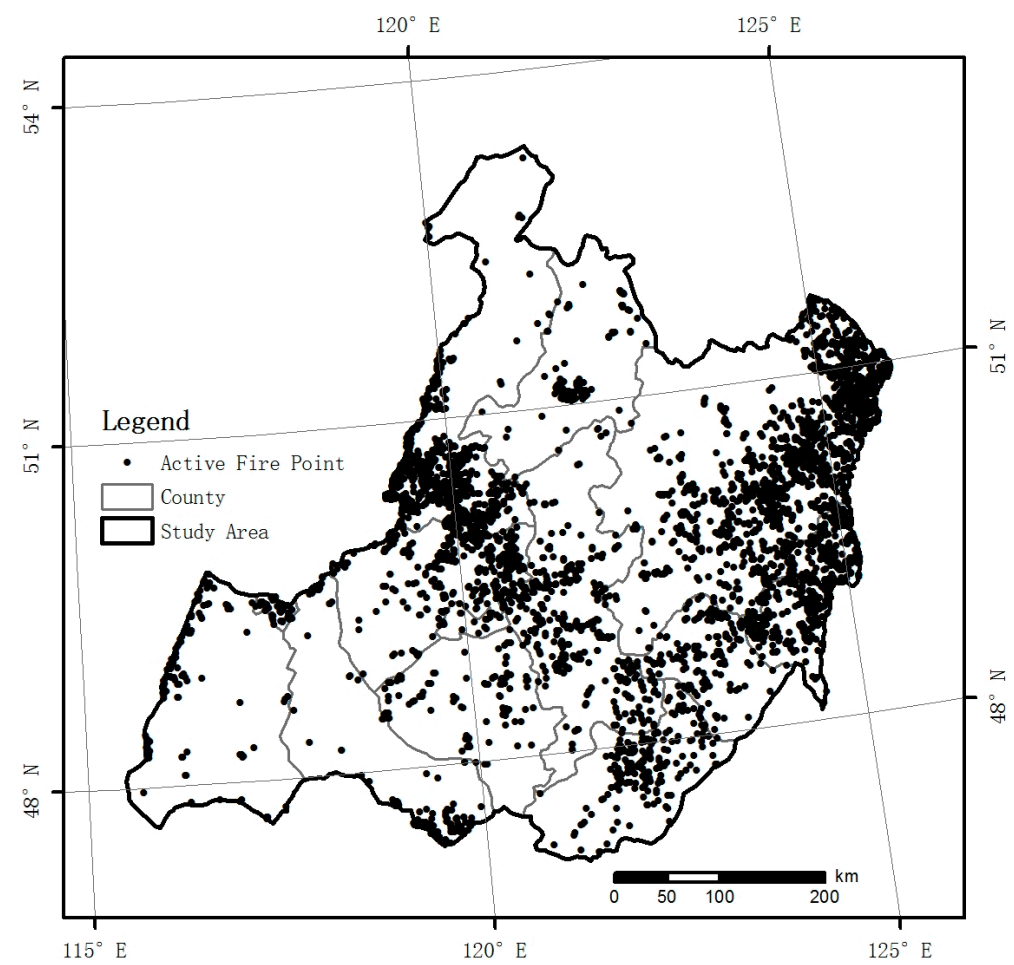

Figure 2. Distribution of grassland active fires in HulunBuir from 2000 to 2014.

Table 2. Monthly occurrences of grassland active fire from 2000 to 2014 .

\begin{tabular}{ccccccccccccc}
\hline Year/Month & $\mathbf{1}$ & $\mathbf{2}$ & $\mathbf{3}$ & $\mathbf{4}$ & $\mathbf{5}$ & $\mathbf{6}$ & $\mathbf{7}$ & $\mathbf{8}$ & $\mathbf{9}$ & $\mathbf{1 0}$ & $\mathbf{1 1}$ & $\mathbf{1 2}$ \\
\hline 2000 & 0 & 0 & 91 & 198 & 55 & 187 & 93 & 29 & 191 & 61 & 8 & 0 \\
2001 & 0 & 1 & 49 & 71 & 6 & 4 & 2 & 3 & 53 & 5 & 12 & 0 \\
2002 & 0 & 16 & 46 & 17 & 9 & 14 & 6 & 43 & 49 & 29 & 70 & 0 \\
2003 & 0 & 15 & 284 & 83 & 289 & 53 & 5 & 0 & 1 & 3 & 0 & 0 \\
2004 & 0 & 0 & 7 & 38 & 5 & 8 & 14 & 34 & 9 & 14 & 8 & 1 \\
2005 & 0 & 0 & 82 & 30 & 11 & 17 & 3 & 34 & 171 & 24 & 0 & 0 \\
2006 & 0 & 0 & 15 & 93 & 110 & 9 & 1 & 6 & 117 & 12 & 1 & 0 \\
2007 & 1 & 22 & 19 & 131 & 12 & 6 & 1 & 42 & 59 & 3 & 0 & 9 \\
2008 & 0 & 16 & 274 & 58 & 15 & 5 & 1 & 7 & 25 & 5 & 23 & 0 \\
2009 & 0 & 0 & 0 & 94 & 29 & 0 & 2 & 1 & 38 & 59 & 6 & 0 \\
2010 & 0 & 0 & 1 & 50 & 28 & 11 & 5 & 9 & 61 & 105 & 16 & 0 \\
2011 & 0 & 0 & 1 & 171 & 6 & 3 & 15 & 40 & 24 & 1 & 1 & 0 \\
2012 & 1 & 2 & 74 & 44 & 27 & 3 & 1 & 15 & 21 & 6 & 9 & 0 \\
2013 & 0 & 0 & 0 & 48 & 75 & 2 & 2 & 1 & 94 & 97 & 29 & 0 \\
2014 & 0 & 1 & 64 & 135 & 12 & 5 & 3 & 10 & 204 & 44 & 2 & 0 \\
\hline
\end{tabular}

\subsection{Fire Climate Index Model}

Of the 132 months in 2000-2010, 101 months had occurrences of grassland fire, and the total number of grassland active fire points was 4274 . Because the average number of grassland fire points per month was 42 , the number of non-fire points per month was 42 , and the total number of non-fire point in 31 months was 1302.

Based on the logistic regression model, the grassland fire climate index model was constructed with monthly average relative humidity (RH), monthly average temperature (TEM), monthly average wind speed (WS), monthly precipitation (PT), monthly sunshine hours (SH), monthly minimum relative humidity (MRH), monthly number of days with precipitation greater than or equal to $5 \mathrm{~mm}$ (PD), monthly average maximum temperature (MTEM) as the variables impacting fire climate index, 
and the regression coefficient of each climate factor in the model satisfies $P<0.001$. The form of the grassland fire climate index model is given by:

$$
\begin{gathered}
P=1 /(1+\exp (-(2.494-0.005 \times \mathrm{PT}+0.002 \times \mathrm{WS}-0.143 \times \mathrm{TEM}-0.017 \times \mathrm{RH} \\
+0.111 \times \mathrm{MTEM}+0.007 \times \mathrm{SH}-0.088 \times \mathrm{MRH}-0.041 \times \mathrm{PD})))
\end{gathered}
$$

SH, MTEM and WS had positive correlations with the fire climate index. RH, TEM, PT, MRH and PD had negative correlations with the fire climate index. Monthly number of days with precipitation greater than or equal to $1 \mathrm{~mm}$, monthly number of days with precipitation greater than or equal to $2.5 \mathrm{~mm}$, monthly maximum wind speed and monthly maximum daily precipitation had no significant influence on the fire climate index model.

Figure 3 showed the ROC curve of the fire climate index model, and AUC for the fire climate index model was 0.845 (95\% confidence interval (CI): 0.837 0.950), which indicated an ability of the fire climate index model to predict the occurrence of grassland fire.

To verify the fire climate index model, monthly precipitation, monthly average temperature, monthly average relative humidity, monthly average wind speed, monthly sunshine hours, monthly maximum temperature, monthly minimum relative humidity and monthly number of days with precipitation greater than or equal to $5 \mathrm{~mm}$ from January to December of 2011-2014 were subjected to Kriging interpolation and were then substituted into the fire climate index model. The monthly mean values of the climate index of 13 counties from January to December were obtained using statistical tools. We calculated the monthly mean of the fire points in 13 counties in the years 2011-2014, and a Pearson correlation analysis was performed on the monthly mean of the climate index of the corresponding month (Table 3). The Pearson correlation coefficient is 0.578 , which indicates that the fire climate index is positively correlated with the number of grassland fire occurrence, and therefore, the fire climate index can be used to express the grassland fire occurrence in HulunBuir.

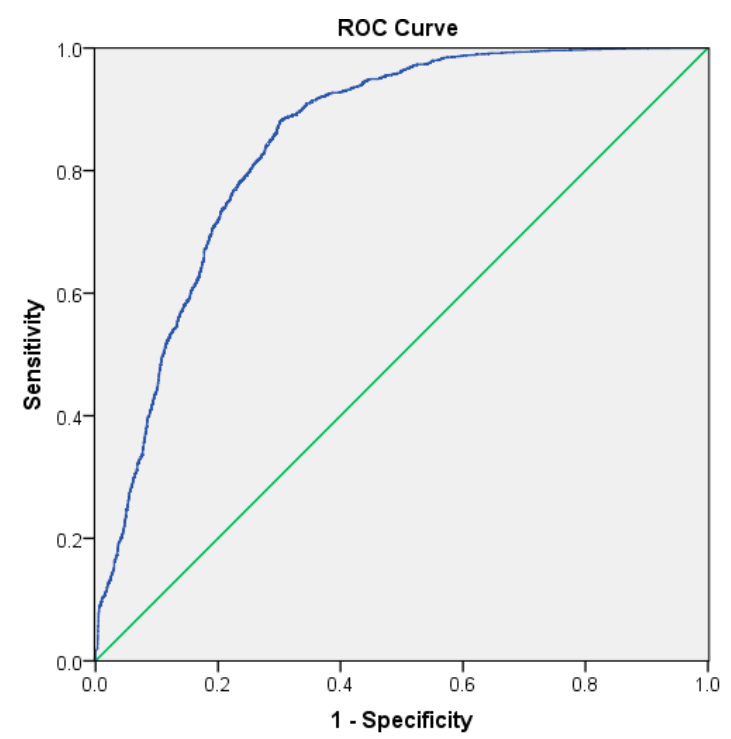

Figure 3. The receiver operator characteristic (ROC) curve of the fire climate index model.

Table 3. Pearson correlation of the number of fire occurrences and fire climate index.

\begin{tabular}{cccc}
\hline Variable & N & Pearson Correlation & Significant Test \\
\hline $\begin{array}{c}\text { Number of fire occurrences \& } \\
\text { Fire climate index }\end{array}$ & 156 & $0.578^{*}$ & 0.000 \\
\hline
\end{tabular}

* Significantly correlated at the 0.01 level (both sides). 


\subsection{The Fire Climate Zones of The Grassland}

The proportion of the study area in each fire climate index zone in each month of an average year is presented in Table 4 and Figure 4. In 2011-2014, the months with higher fire climate indices were April, May and September, October, and in the other months, the fire climate index was lower. December, January and February were months with an extremely low fire climate index zone. In March, the fire climate index decreased from southeast to northwest, the area proportion of the medium fire climate index zone was $57.10 \%$, and the area proportion of the extremely low fire climate index zone was $4.21 \%$. In April, the fire climate index increased from the center to the surroundings, the area proportion of the high fire climate index zone was $41.98 \%$, and the area proportion of the low fire climate index zone was $1.34 \%$. In May, the fire climate index increased from the center to the surroundings; the area proportion of the high fire climate index zone was $50.44 \%$, and the area proportion of the medium fire climate index zones was $6.71 \%$. In June, the fire climate index increased from northeast to southwest, the area proportion of the low fire climate index zone was $49.33 \%$, and the area proportion of the extremely high fire climate index zone was $7.88 \%$. In July, the fire climate index increased from east to west, the area proportion of the low fire climate index zone was $47.13 \%$, and the area proportion of the high fire climate index zones was $6.69 \%$. In August, the fire climate index increased from the center to the surroundings, the area proportion of the medium fire climate index zone was $35.48 \%$, and the area proportion of the extremely low fire climate index zone was $8.92 \%$. In September, the fire climate index increased from the center to the surroundings, the area proportion of the high fire climate index zone was $53.32 \%$, and the area proportion of the medium fire climate index zone was $5.88 \%$. In October, the fire climate index increased from the center to the surroundings, the area proportion of the high fire climate index zone was $50.89 \%$, and the area proportion of the low fire climate index zone was $3.16 \%$. In November, the area proportion of the extremely low fire climate index zone was $93.20 \%$, and the area proportion of the low fire climate index zone was $6.80 \%$.

On the whole, the zones with higher fire climate index are mainly distributed in Xin Barag Youqi, Xin Barag Zuoqi, Zalantun Shi, Oroqen Zizhiqi, and Molidawa Zizhiqi; the zones with medium fire climate index are mainly distributed in Chen Barag Qi, Ewenkizu Zizhiqi, Manzhouli Shi, and Arun Qi; and the zones with lower fire climate index are mainly distributed in Genhe Shi, Ergun city, Yakeshi Shi, and Hailar Shi.

Table 4. The percent of area of grassland fire climate distribution zones.

\begin{tabular}{cccccc}
\hline & $\begin{array}{c}\text { Extremely Low } \\
\text { Fire Climate Index } \\
\text { Zone (\%) }\end{array}$ & $\begin{array}{c}\text { Low Fire } \\
\text { Climate Index } \\
\text { Zone (\%) }\end{array}$ & $\begin{array}{c}\text { Medium Fire } \\
\text { Climate Index } \\
\text { Zone (\%) }\end{array}$ & $\begin{array}{c}\text { High Fire } \\
\text { Climate Index } \\
\text { Zone (\%) }\end{array}$ & $\begin{array}{c}\text { Extremely High } \\
\text { Fire Climate Index } \\
\text { Zone (\%) }\end{array}$ \\
\hline January & 100 & 0.00 & 0.00 & 0.00 & 0.00 \\
February & 100 & 0.00 & 0.00 & 0.00 & 0.00 \\
March & 4.21 & 21.40 & 57.10 & 17.30 & 0.00 \\
April & 0.00 & 1.34 & 24.79 & 41.98 & 31.89 \\
May & 0.00 & 0.00 & 6.71 & 50.44 & 42.85 \\
June & 0.00 & 49.33 & 30.55 & 12.24 & 7.88 \\
July & 20.31 & 47.13 & 25.88 & 6.69 & 0.00 \\
August & 8.92 & 33.54 & 35.48 & 22.06 & 0.00 \\
September & 0.00 & 0.00 & 5.88 & 53.32 & 40.80 \\
October & 0.00 & 3.16 & 31.49 & 50.89 & 14.46 \\
November & 93.20 & 6.80 & 0.00 & 0.00 & 0.00 \\
December & 100 & 0.00 & 0.00 & 0.00 & 0.00 \\
\hline
\end{tabular}




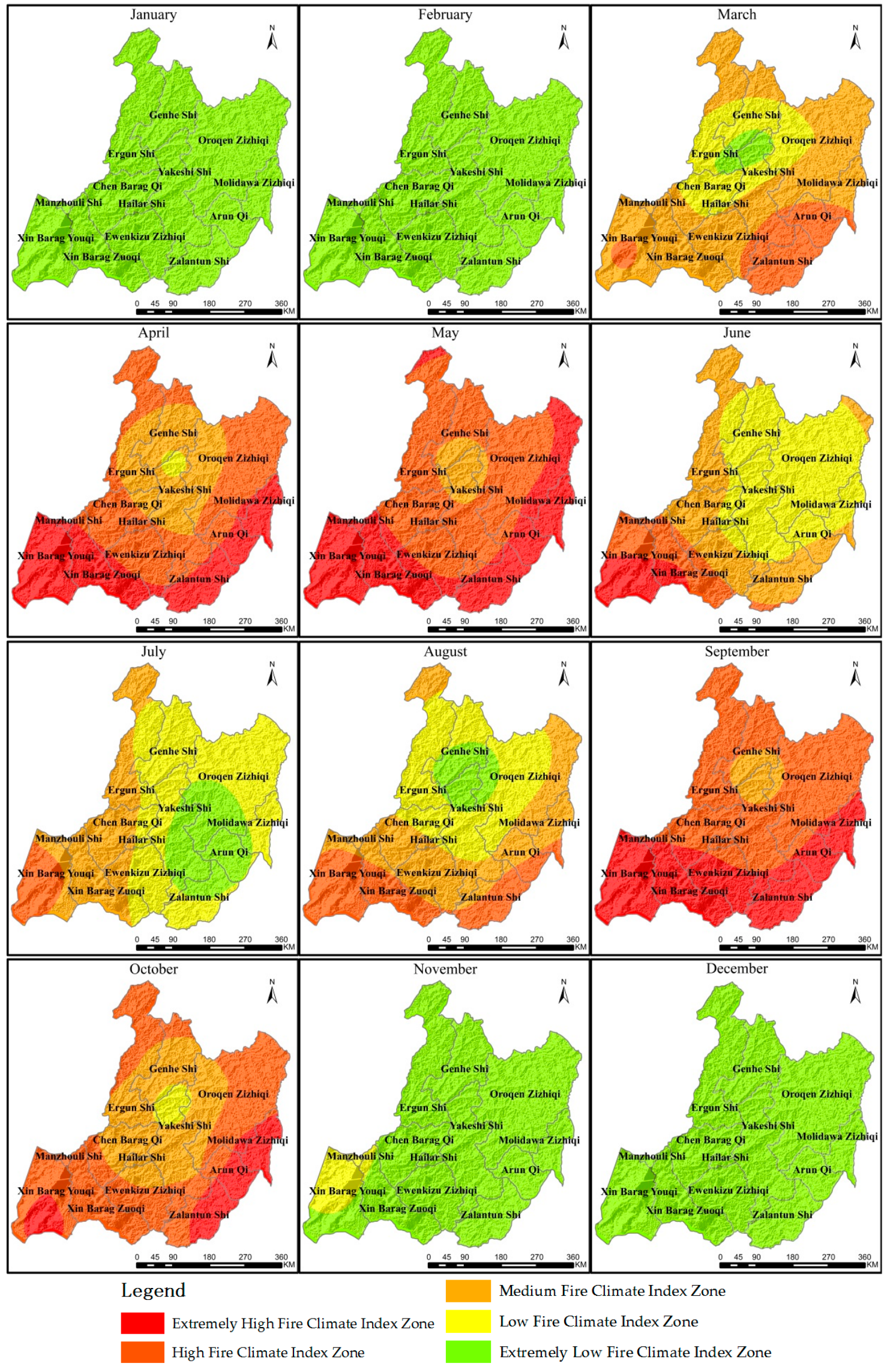

Figure 4. The distribution of monthly grassland fire climate in HulunBuir. 


\section{Discussion}

Monitoring weather plays an important role in the forecast and early warning of fire hazards, but only for the short-term effects of fire weather on the role of grassland fire occurrence, while its effects on the medium- and long-term fire forecast are not obvious. In this paper, on a monthly time scale, we established the fire climate index model, and the relationship between the monthly fire climate index and the occurrence of grassland fire was analyzed; this can be used to improve the fire warning system and provide a scientific basis for mid-to-long-term grassland fire prevention.

From the results of this study, monthly precipitation, monthly average temperature, monthly average relative humidity, monthly minimum relative humidity and monthly number of days with precipitation greater than or equal to $5 \mathrm{~mm}$ are negatively correlated with the grassland fire climate index. The greater the precipitation, the greater the humidity, and the higher the moisture content of vegetation, the less likely grassland fire is to occur. In the opposite scenario, grassland fire is more likely to occur. This is consistent with the results of previous studies $[27,48]$.

The correlation between the grassland fire climate index and monthly average temperature is negative, which is not consistent with the previous results $[49,50]$. HulunBuir has a temperate continental climate, and the precipitation and temperature are positively correlated, i.e., when the temperature increases, the precipitation increases. December, January and February are cold, and the temperature is at its lowest; March, April and May are spring months, and the temperature and precipitation increase slowly; June, July and August are summer months, and the temperature and precipitation are at their highest; and September, October and November are autumn, and the temperature and precipitation decrease. Meanwhile, grassland fire occurred mainly in spring and autumn; in summer, grassland fire occurred less, and in winter, the number of grassland fires was the least. In the study area, the monthly average temperature in April and May was lower than that in June, July and August, but the number of grassland fires that occurred in April and May was more than that in June, July and August. The main reason was with the increase in temperature, the precipitation increased, and the vegetation entered a "green-up" period after the growing season, which increased the water content of the vegetation, so grassland fire was less likely. Therefore, it is reasonable to obtain a negative correlation between the fire climate index and the monthly average temperature in the study area.

The fire climate index of grassland was positively correlated with the monthly maximum temperature, monthly sunshine hours and monthly average wind speed; this result is similar with other findings [8,51]. This phenomenon occurs because long hours of sunshine, high temperatures and high winds can accelerate the evaporation of water, increasing the likelihood of fire.

Within the study area, the zones with higher fire climate index are mainly distributed in Xin Barag Youqi, Xin Barag Zuoqi, Zalantun Shi, Oroqen Zizhiqi, and Molidawa Zizhiqi; the zones with medium fire climate index are mainly distributed in Chen Barag Qi, Ewenkizu Zizhiqi, Manzhouli Shi, and Arun Qi; and the zones with lower fire climate index are mainly distributed in Genhe Shi, Ergun city, Yakeshi Shi, and Hailar Shi. However, there are few occurrences of grassland fire in some zones with higher fire climate index, and the number of fire occurrences corresponding to low fire climate index may be very high, which is also the reason why the Pearson correlation coefficient is not very high. The reason for this is that the occurrence of grassland fire is affected by many factors, but this paper only considered the influence of climate factors on grassland fire and did not consider the factors such as fuel, human activities, vegetation type and land use $[19,52,53]$. As a result, there are appreciable differences between fire climate index and fire occurrence frequency in some regions.

\section{Conclusions}

HulunBuir, with its temperate continental climate, is the area studied in this paper. On the monthly time scale, based on the logistic regression method, we used the MODIS active fire data product and the relevant climate data to establish a model of grassland fire climate index. Monthly precipitation, monthly average temperature, monthly average relative humidity, monthly minimum relative 
humidity and monthly number of days with precipitation greater than or equal to $5 \mathrm{~mm}$ are all negatively correlated with the grassland fire climate index. The fire climate index of grassland is positively correlated with the monthly maximum temperature, monthly sunshine hours and monthly average wind speed. The results of this study show that the fire occurrence index can be used to represent the fire occurrence in the HulunBuir area during the month, which can provide a scientific understanding of the temporal and spatial regularity of grassland fire for the purpose of forecast and early warning of grassland fire. The fire climate method in this paper provides a way to study the relationship between mid-to-long-term climate change and grassland fire occurrence.

Acknowledgments: This work was supported by the National Natural Science Foundation of China (Grant number 41571489), the National Key Research and Development Project (Grant number 2016YFA0602301), the National Natural Science Foundation of China (Grant numbers 41501449 and 41601438) and National Science and Technology Major Project of China (Grant number 2015ZX07201-008-10).

Author Contributions: Meifang Liu is the principal author of this manuscript and responsible for the writing and analysis. Zhengxiang Zhang is responsible for the experiment ideas. Jianjun Zhao and Xiaoyi Guo contributed analysis tool and the reviewing of the manuscript. Gang Tan and Jihong Yang are responsible for the collection of data.

Conflicts of Interest: The authors declare no conflict of interest.

\section{References}

1. Bowman, D.M.J.S.; Balch, J.K.; Artaxo, P.; Bond, W.J.; Carlson, J.M.; Cochrane, M.A.; D'Antonio, C.M.; DeFries, R.S.; Doyle, J.C.; Johnston, F.H.; et al. Fire in the Earth system. Science 2009, 324, 481-484. [CrossRef] [PubMed]

2. Flannigan, M.D.; Krawchuk, M.A.; Groot, W.J.D.; Wotton, B.M.; Gowman, L.M. Implications of changing climate for global wildland fire. Int. J. Wildland Fire 2009, 18, 483-507. [CrossRef]

3. Finch, J.; Marchant, R. A palaeoecological investigation into the role of fire and human activity in the development of montane grasslands in East Africa. Veg. Hist. Archaeobotany 2011, 20, 109-124. [CrossRef]

4. Dimitrakopoulos, A.P.; Bemmerzouk, A.M.; Mitsopoulos, I.D. Evaluation of the Canadian fire weather index system in an eastern Mediterranean environment. Meteorol. Appl. 2011, 18, 83-93. [CrossRef]

5. Hantson, S.; Padilla, M.; Corti, D. Strengths and weaknesses of MODIS hotspots to characterize global fire occurrence. Remote Sens. Environ. 2013, 131, 152-159. [CrossRef]

6. Liu, X.Y.; Long, R.J.; Shang, Z.H. Study on Grassland Ecosystem Service Function and Its Valuation Method. J. Anim. Sci. Vet. Med. 2011, 20, 167-174.

7. Liu, X.; Zhang, J.; Cai, W. Information diffusion-based spatio-temporal risk analysis of grassland fire disaster in northern China. Knowl.-Based Syst. 2010, 23, 53-60. [CrossRef]

8. Beverly, J.L.; Martell, D.L. Characterizing extreme fire and weather events in the Boreal Shield ecozone of Ontario. Agric. For. Meteorol. 2005, 133, 5-16. [CrossRef]

9. Duffy, P.A.; Walsh, J.E.; Graham, J.M.; Mann, D.H.; Rupp, T.S. Impacts of large-scale atmospheric-ocean variability on Alaskan fire season severity. Ecol. Appl. 2005, 15, 1317-1330. [CrossRef]

10. Whitlock, C.; Shafer, S.L.; Marlon, J. The role of climate and vegetation change in shaping past and future fire regimes in the northwestern US and the implications for ecosystem management. For. Ecol. Manag. 2003, 178, 5-21. [CrossRef]

11. Nunes, A.N. Regional variability and driving forces behind forest fires in Portugal an overview of the last three decades (1980-2009). Appl. Geogr. 2012, 34, 576-586. [CrossRef]

12. Viegas, D.X.; Piñol, J.; Viegas, M.T.; Ogaya, R. Estimating live fine fuel moisture content using meteorologically-based indices. Int. J. Wildland Fire 2001, 10, 223-240. [CrossRef]

13. Pausas, J.G. Changes in Fire and Climate in the Eastern Iberian Peninsula (Mediterranean Basin). Clim. Chang. 2004, 63, 337-350. [CrossRef]

14. Giuseppe, A.; João, R.M.; Marco, T.; Raffaella, L. Assessing long-term fire risk at local scale by means of decision tree technique. J. Geophys. Res. 2006, 111, 979-982.

15. Meunier, J.; Romme, W.H.; Brown, P.M. Climate and land-use effects on wildfire in northern Mexico, 1650-2010. For. Ecol. Manag. 2014, 325, 49-59. [CrossRef] 
16. Iniguez, J.M.; Swetnam, T.W.; Baisan, C.H. Spatially and temporally variable fire regime on Rincon Peak, Arizona, USA. Fire Ecol. 2009, 5, 3-21. [CrossRef]

17. Ireland, K.B.; Stan, A.B.; Fulé, P.Z. Bottom-up control of a northern Arizona ponderosa pine forest fire regime in a fragmented landscape. Landsc. Ecol. 2012, 27, 983-997. [CrossRef]

18. Snyman, H.A. Estimating the short-term impact of fire on rangeland productivity in a semi-arid climate of South Africa. J. Arid Environ. 2004, 59, 685-697. [CrossRef]

19. Sheuyange, A.; Oba, G.; Weladji, R.B. Effects of anthropogenic fire history on savanna vegetation in northeastern Namibia. J. Environ. Manag. 2005, 75, 189-198. [CrossRef] [PubMed]

20. Zhou, D.W.; Zhang, Z.S. Grass fire burning, fire behavior and fire climate. Chin. Grassl. 1996, 3, 74-77.

21. Fu, Z.Q.; Yang, Y.X.; Dai, E.F. Study on Dynamics of Dry-grassland Fire and Regionalization of Fire Risk in Inner. China J. Agric. Resour. Reg. Plan. 2001, 22, 18-22.

22. Guo, Z.; Fang, W.; Tan, J.; Shi, X. A Time-Dependent Stochastic Grassland Fire Ignition Probability Model for Hulun Buir Grassland of China. Chin. Geogr. Sci. 2013, 23, 445-459. [CrossRef]

23. Irvine, D.J.; Mccluskey, J.A.; Robinson, I.M. Fire hazards and some common polymers. Polym. Degrad. Stab. 2000, 67, 383-396. [CrossRef]

24. Tang, L.H.; Fang, L.M.; Xia, K.; Xu, A.J. Forest fire rating system indicated by human activities based on spatial analysis of GIS. J. Zhejiang For. Sci. Technol. 2007, 27, 42-46.

25. Snyder, R.L.; Spano, D.; Duce, P.; Baldocchi, D.; Xu, L. A fuel dryness index for grassland fire-danger assessment. Agric. For. Meteorol. 2006, 139, 1-11. [CrossRef]

26. Littell, J.S.; McKenzie, D.; Peterson, D.L.; Westerling, A.L. Climate and wildfire area burned in western U.S. ecoprovinces, 1916-2003. Ecol. Appl. 2009, 19, 1003-1021. [CrossRef] [PubMed]

27. Trouet, V.; Taylor, A.H.; Wahl, E.R.; Skinner, C.N.; Stephens, S.L. Fire-climate interactions in the American West since 1400 CE. Geophys. Res. Lett. 2010, 37, 90-98. [CrossRef]

28. Westerling, A.L.; Gershunov, A.; Brown, T.J.; Cayan, D.R.; Dettinger, M.D. Climate and Wildfire in the Western United States. Bull. Am. Meteorol. Soc. 2010, 84, 595-604. [CrossRef]

29. Fu, Z. Research on Fire-risk Climate Zoning and Fire Management Measures on Grasslands in Inner Mongolia. J. Catastrophol. 2001, 16, 19-22.

30. Liu, Z.; Wimberly, M.C. Climatic and Landscape Influences on Fire Regimes from 1984 to 2010 in the Western United States. PLoS ONE 2015, 10, e0140839. [CrossRef] [PubMed]

31. Bradstock, R.A.; Cohn, J.S.; Gill, A.M.; Bedward, M.; Lucas, C. Prediction of the probability of large fires in the Sydney region of south-eastern Australia using fire weather. Int. J. Wildland Fire 2010, 18, 932-943. [CrossRef]

32. Westerling, A.L.; Hidalgo, H.G.; Cayan, D.R.; Swetnam, T.W. Warming and Earlier Spring Increase Western U.S. Forest Wildfire Activity. Science 2006, 313, 940-943. [CrossRef] [PubMed]

33. Mollicone, D.; Eva, H.D.; Achard, F. Ecology: Human role in Russian wild fires. Nature 2006, 440, $436-437$. [CrossRef] [PubMed]

34. Zhao, F.J.; Shu, L.F.; Tian, X.R. A Review of Studies on Climate Change and Forest Fire. For. Fire Prev. 2005, 4, 19-21.

35. Finney, M.A.; Seli, R.C.; Mchugh, C.W.; Ager, A.A.; Bahro, B.; Agee, J.K. Simulation of long-term landscape-level fuel treatment effects on large wildfires. Int. J. Wildland Fire 2007, 16, 712-727. [CrossRef]

36. Wotton, B.M.; Gumpertz, M. Interpreting and using outputs from the Canadian Forest Fire Danger Rating System in research applications. Environ. Ecol. Stat. 2009, 16, 107-131. [CrossRef]

37. Fraser, R.H.; Li, Z. Estimating fire-related parameters in boreal forest using SPOT VEGETATION. Remote Sens. Environ. 2002, 82, 95-110. [CrossRef]

38. Chu, P.S.; Yan, W.; Fujioka, F. Fire-climate relationships and long-lead seasonal wildfire prediction for Hawaii. Int. J. Wildland Fire 2002, 11, 25-31. [CrossRef]

39. Hoinka, K.P.; Carvalho, A.; Miranda, A.I. Regional-scale weather pattern and wildland fires in Central Portugal. Int. J. Wildland Fire 2009, 18, 36-49. [CrossRef]

40. Liu, Z.; Wimberly, M.C. Direct and indirect effects of climate change on projected future fire regimes in the western United States. Sci. Total Environ. 2016, 542, 65-75. [CrossRef] [PubMed]

41. Riley, K.L.; Loehman, R.A. Mid-21st-century climate changes increase predicted fire occurrence and fire season length, Northern Rocky Mountains, United States. Ecosphere 2016, 7, e01543. [CrossRef] 
42. Bigio, E.R.; Swetnam, T.W.; Baisan, C.H. Local-scale and regional climate controls on historical fire regimes in the San Juan Mountains, Colorado. For. Ecol. Manag. 2016, 360, 311-322. [CrossRef]

43. Curt, T.; Borgniet, L.; Ibanez, T.; Moron, V.; Hély, C. Understanding fire patterns and fire drivers for setting a sustainable management policy of the New-Caledonian biodiversity hotspot. For. Ecol. Manag. 2015, 337, 48-60. [CrossRef]

44. LAADS. Available online: https://ladsweb.nascom.nasa.gov/ (accessed on 14 March 2017).

45. Open Spatial Data Sharing Project RADI. Available online: http://ids.ceode.ac.cn/ (accessed on 14 March 2017).

46. Fawcett, T. An introduction to ROC analysis. Pattern Recognit. Lett. 2006, 27, 861-874. [CrossRef]

47. Zou, H.X.; Qin, F.; Cheng, Z.K.; Wang, X.Y. Algorithm for Generating ROC Curve of Two-Classifier. Comput. Technol. Dev. 2009, 19, 109-112.

48. Jian, W.; Song, W.; Zheng, H.; Telesca, L.; Lasaponara, R. Temporal scaling behavior of human-caused fires and their connection to relative humidity of the atmosphere. Ecol. Model. 2010, 221, 85-89.

49. Zhang, Z.X.; Zhang, H.Y.; Zhou, D.W. Using GIS spatial analysis and logistic regression to predict the probabilities of human-caused grassland fires. J. Arid Environ. 2010, 74, 386-393. [CrossRef]

50. Hamilton, L.C.; Hartter, J.; Keim, B.D. Wildfire, climate, and perceptions in Northeast Oregon. Reg. Environ. Chang. 2016, 16, 1819-1832. [CrossRef]

51. Goff, H.L.; Flannigan, M.D.; Bergeron, Y. Potential changes in monthly fire risk in the eastern Canadian boreal forest under future climate change. Can. J. For. Res. 2009, 39, 2369-2380. [CrossRef]

52. Zhang, Z.X.; Zhang, H.Y.; Li, D.X.; Xu, J.; Zhou, D. Spatial distribution pattern of human-caused fires in Hulun Buir grassland. Acta Ecol. Sin. 2013, 33, 2023-2031. [CrossRef]

53. Amatulli, G.; Peréz-Cabello, F.; Riva, J.D.L. Mapping lightning/human-caused wildfires occurrence under ignition point location uncertainty. Ecol. Model. 2007, 200, 321-333. [CrossRef]

(C) 2017 by the authors. Licensee MDPI, Basel, Switzerland. This article is an open access article distributed under the terms and conditions of the Creative Commons Attribution (CC BY) license (http:/ / creativecommons.org/licenses/by/4.0/). 